\title{
Modeling Student Concern for Professional Online Image
}

\author{
Robert Miller $^{1}$, Michelle Salmona ${ }^{2}$ and James Melton ${ }^{1}$ \\ ${ }^{1}$ Central Michigan University, Mount Pleasant, MI, USA \\ ${ }^{2}$ Australian National University, Canberra, Australia
}

\begin{abstract}
The purpose of this paper is to investigate the factors that influence a student's concern for presenting a professional online image. Drawing on existing research, the paper develops a model of professional online image concern which is then validated through a survey-based field study. The survey was administered to students at two large universities in Australia and the Midwest United States. The results show that privacy concern, social factors and being on the job market are factors which significantly influence a student's concern for presenting a professional online image. The results presented in the paper shed light on the motivations of students as they use social networking sites. Through an understanding of these motivations, faculties will be better able to design interventions to modify negative posting behavior. Likewise, understanding student motivations will allow hiring managers and other practitioners to use social networking more effectively as a candidate screening tool.
\end{abstract}

Keywords: Social networks, professional online image concern, privacy concern, social factors.

\section{Introduction}

Since their introduction a little over a decade ago, the growth of social networking sites has been nothing less than phenomenal. Sites such as MySpace and Facebook claim millions of active users in the U.S. and, increasingly, around the world. Social networking users represent almost every possible demographic. One group which has been especially drawn to these sites is college students. College students use social networking sites for a variety of reasons from staying in contact with old friends to connecting with classmates and checking pictures (Miller, Parsons and Lifer, 2010). For many students, these sites have become an essential part of their day-to-day lives.

Although students may view their online activities as inconsequential, many fail to consider the fact that the content posted in their profiles may be viewed by people other than their friends. This lack of consideration often leads students to post content that presents a less-than-professional online image. Given that many potential employers now routinely screen candidate profiles, a negative online image can be detrimental to a successful job search.

According to a recent survey of more than 600 human resources and recruiting professionals, $70.3 \%$ of respondents always or occasionally review a candidate's social networking profile (Jobvite, 2010). Using profiles from social networking sites as an inexpensive background check is quickly becoming a standard business practice. In fact, companies are now being advised to use social networking sites when making hiring decisions (Elzweig and Peeples, 2009).

Copyright (C) 2012 Robert Miller, Michelle Salmona and James Melton. This is an open access article distributed under the Creative Commons Attribution License unported 3.0, which permits unrestricted use, distribution, and reproduction in any medium, provided that original work is properly cited. Contact author: Robert Miller E-mail: mille5re@cmich.edu 
These checks can often give employers access to personal information that they would be prohibited from asking a candidate for during an interview. Examples include information about marital status, sexual orientation, religious affiliation, etc. Sometimes the checks even produce eyeopening results about a candidate. An example from the Boston Globe cites a marketing manager who decided not to hire a job candidate after a check of MySpace uncovered photos of the candidate Jell-O wrestling (Aucoin, 2007).

Stories like this are hardly rare. In fact, 35\% of employers reported they have found content on social networking sites that caused them not to hire a candidate (Haefner, 2009). Given the extensive coverage of this issue by the press and on many college campuses, it would be difficult for students to claim ignorance about the severity of the problem. To the contrary, Miller et al. (2010) found that students appear to realize that the images they present in their online profiles are often inappropriate when viewed by a potential employer. The researchers termed this behavior the "posting paradox" students know the content they post creates an unprofessional online image but they choose to post it anyway. Given these findings and the potential threat of inappropriate posting behavior to students' professional futures, one would expect a great deal of research extending investigation of this topic. Yet, as will be explained below, the research on this topic remains sparse. Continued study of the following question is needed: Why do some students appear to have no concern for presenting a professional online image, even when they realize that their online image may have a negative impact on their employability?

This paper contributes to the discussion of online image by investigating the factors that affect the information students share online and the image that information creates. The paper begins by discussing social networking sites and their astronomical growth. The paper then addresses the issue of online image before presenting the research model. The model is then validated using a surveybased field study. The paper ends with a discussion of the results as well as implications and areas for future research.

\section{Social Networking}

Social networking sites allow users to create online profiles where they can post photos, music, status updates, etc. Users can also specify a list of other users (friends) with whom they share a connection. Through these friend connections, users can view and post information on each other's profiles. Although the first social networking sites appeared in the mid 1990s (e.g. Classmates.com in 1995 and SixDegrees.com in 1997), they did not become a significant Internet presence until MySpace and Facebook were introduced in 2003 and 2004, respectively.

Since their introductions, both sites have grown substantially. According to TechCrunch, at the beginning of 2009, MySpace had approximately 125 million users (Arrington, 2009). Although Facebook may have gotten a later start, as of January 2012, it was reporting 800 million active users (Facebook, 2012). Popular social networking sites outside North America include Badoo in Europe and Latin America, with approximately 137 million users (Badoo, 2012), and Orkut in India and Brazil, with over 100 million users (Economic Times, 2009).

Given the number of users, and the continued growth of social networking sites, it is easy to argue that they constitute a significant social phenomenon. Such a phenomenon needs to be examined if we are to understand it better. While social networking sites claim users from almost every possible demographic, it is the large number of college students who are of particular interest to this paper. Not only are they intense users of this technology, as has been mentioned; they are also a group with great potential risk of damage to career 
prospects and, even more important, a group that has great promise for intervention by faculty and others at their institutions.

\section{Students and Online Image}

As a diverse group, students do not use social networking sites for the same reasons. Likewise, the image that these students portray in their profiles can be quite different. After reviewing a series of Facebook profiles, Peluchette and Karl (2010) identified six types of images commonly portrayed in student profiles. These images included: a) appealing to the opposite sex; b) wild; c) fun and friendly; d) offensive; e) intelligent; and f) hardworking. Obviously, some of these images would be less appropriate for a student entering the job market.

Karl, Peluchette and Schlaegel (2010) argue that self-presentation is an important aspect of social networking and the image that students choose to portray. Essentially, students who are less concerned about how their profiles are viewed by employers are more likely to present images that are appealing to the opposite sex, wild, fun and/or offensive. Students who are concerned with the way employers, or other authority figures, view their profiles are more likely to present an image that is intelligent and/or hardworking.

\section{Professional Online Image Factors}

In order to better understand professional online image concern, it is first necessary to examine the factors which act as its antecedents. While any number of factors could be considered, the model proposed herein (see Figure 1) draws on previous research to identify factors with strong theoretical bases. Specifically, the model examines the following factors: time to graduation, social factors, privacy concern and being on the (job) market. The following sections will describe each of these factors and their proposed relationships to professional online image concern.

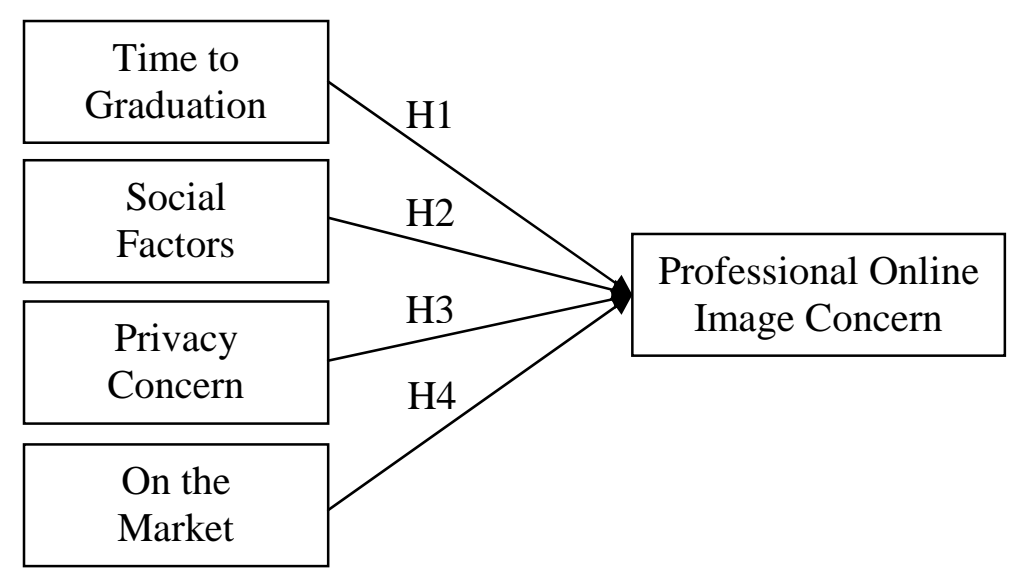

Figure 1: Research Model

H1: Time to graduation has a negative relationship with professional online image concern.

H2: Social factors have a positive relationship with professional online image concern.
H3: Privacy concern has a positive relationship with professional online image concern.

H4: Being on the market has a positive relationship with professional online image concern. 


\section{Time to Graduation}

Time to graduation represents the student's temporal distance to leaving college and entering the job market. Previous research has shown that the earlier students are in their college careers, the more likely they are to post material that they acknowledge would be seen as inappropriate by potential employers (Miller et al., 2010). In their study, Miller et al. (2010) found that freshmen (4+ years to graduation) were less comfortable than seniors (1 year to graduation) with the prospect of having employers view their profiles. The researchers theorized that this was due to the fact that the freshmen had posted content that presented less professional images than the seniors. The researchers further theorized that the seniors may have been more comfortable with their profiles because they had "cleaned them up" in preparation for entering the job market.

This type of temporal-based behavior is inline with the Construal Level Theory (CLT) as proposed by Trope and Liberman (2000). According to CLT, temporal distance changes the way people respond to future events by changing the way that they mentally represent those events. Specifically, events in the future will be represented in an abstract fashion while events that are closer will be represented in a more concrete fashion. Applying CLT to online image, it could be argued that students who are further from entering the job market construe their post-graduation activities in an abstract way with very little detail. They may not consider the interview process that they will be going through or the fact that recruiters may actually search for them on social networking sites. With an abstract view of the future, students may not see their online image as being particularly risky. As these students approach graduation, they begin to view the process of getting a job in a much more concrete way. This may cause them to remove inappropriate content because they now realize their online image could put their job search in jeopardy.
Essentially, as time to graduation nears, the student's concern for his, or her, professional online image will increase. In line with CLT, Figure 1 proposes that there will be a negative relationship between time to graduation and professional online image concern.

\section{Social Factors}

Triandis (1980) define social factors as "the individual's internalization of the reference group's subjective culture, and specific interpersonal agreements that the individual has made with others, in specific social situations" (p. 210). The subjective culture consists of the group's shared norms, roles and values. Through social factors, these norms, roles and values affect the behavior of the individuals in the group. Individuals wanting to identify with the group, and maintain a positive image among group members, will feel compelled to adopt and promote the group's norms, roles and values.

In the case of college students and social networking, social factors represent the effect that the posting behavior of a student's network of friends has on that student's own posting behavior. Essentially, the posting behavior of a student's friends will directly affect what the student posts. If the student's friends post content in their profiles that is less than professional, the student is also likely to post unprofessional content in order to comply with the group norm. On the other hand, if the student's friends are concerned about presenting professional images online, then the student is likely to do the same. Based on this reasoning, Figure 1 proposes that there will be a positive relationship between social factors and professional online image concern.

\section{Privacy Concern}

Privacy concern can be defined as the desire to keep personal information from being disclosed to others. In the context of college students and their online images, privacy concern describes the desire of a student to 
keep personal information from being viewed by people outside his or her network of friends (Miller et al., 2011). While the desire for privacy may seem universal, for many social networking users, it does not appear to be a major concern. As evidence of this, a recent study by the Ponemon Institute found that $65 \%$ of social networking users did not use a high privacy setting (Business Wire, 2010).

In actuality, researchers have found that privacy concern is a highly subjective measure (Buchanan et al., 2007). It varies from person to person based on each individual's perceptions and values. This means that student concern for privacy is likely to span the gamut from highly concerned to completely unconcerned. In addition, even those students who are concerned about privacy may have a difficult time securing their profiles. Social networking sites do not make profiles private by default. Since the goal of social networking sites is to connect people, sharing information between users is a fundamental part of the process. As more profiles become private, it becomes harder for users to share information and for the network to grow. Social networking sites, therefore, have a vested interest in keeping privacy at a minimum. Users who wish to make their profiles private often have to go through a number of steps which can be both confusing and time-consuming.

Even when users are concerned enough about privacy to secure their profiles, privacy breaches are still possible. Social networking sites have been breached numerous times, revealing information that users thought were secure (e.g., Newman, 2010). Since privacy can't be guaranteed, it can be argued that students with an elevated concern for privacy would also be concerned with the image presented in their online profile. In line with this reasoning, Figure 1 proposes a positive relationship between privacy concern and professional online image concern.

\section{On the Market}

"On the market" represents the student's perception that they have entered the job market for their first professional position. While it might seem that a student's time to graduation and their perception of being on the job market would be highly correlated, this is not necessarily true. Although many students begin applying for professional jobs during their senior year (close to graduation), there are some students who begin the job search much earlier, seeking coops and internships as early as their freshman year (far from graduation). Given the fact that students make the decision to enter the job market at different times, often irrespective of their graduation date, time to graduation and being on the market can be considered as two separate constructs.

Once a student considers him, or herself, to be on the market; his, or her, posting behavior is likely to change. This change in behavior is also supported by Construal Level Theory. Once the student is on the market, then the prospect of a job search moves from the future to the present. This makes the search much more concrete in the student's mind. As a result, the student will change his, or her, behavior to conform to the job-seeking goal. In terms of social networks, this should result in a change to posting content that creates a more professional online image. For this reason, Figure 1 proposes a positive relationship between being on the market and professional online image concern.

\section{Instrumentation Design and Validation}

In order to validate the model proposed in Figure 1, a survey instrument was developed to capture the constructs of interest. Where possible, the items used for each construct were modified from existing measures. The initial list of these items is given in Table 1. 
The items for the social factors construct were modified from the instrument developed by Thompson, Higgins and Howell (1991). The privacy concern items were based on the instrument developed by Buchanan et al. (2007). The items for professional online image concern were developed from the self-presentation items originally created by Krasnova, Spiekermann, Koroleva and Hildebrand (2010). All of these items use a seven point Likert-type scale with the anchors "strongly agree" and "strongly disagree." A seven point scale was chosen because it captures more variance as compared to a five point scale.

'Time to graduation' was captured with a multiple-choice question with possible answers of less than one year; one year; two years; three years; four years; and more than four years. The 'on the market' construct was captured with a simple yes/no item.

Table 1: Initial Items by Construct

\section{Social Factors}

1. My close friends maintain profiles that present professional images.

2. The profiles of my close friends would be acceptable to potential employers.

3. My close friends work hard to appear professional in their profiles.

4. Potential employers would be impressed with the professional profiles of my close friends.

5. My close friends present professional images in their profiles.

\section{Privacy Concern}

1. I don't want people outside my network of friends viewing my profile.

2. I restrict access to my profile to the friends in my network.

3. People outside my network of friends should not be able to view my profile.

4. My profile should only be viewed by my network of friends.

5. It is important to keep people outside my network from viewing my profile.

\section{Professional Online Image Concern}

1. I want to present a professional image in my profile.

2. It is important to maintain a professional image online.

3. People who view my profile will see me as a professional.

4. I work hard to maintain a professional image in my profile.

5. My online image is important to my future.

Once the instrument was developed, it was validated in a field study using a sample drawn from undergraduate students enrolled in business courses at two large universities in Australia (University 1) and the Midwest United States (University 2). The survey was administered using both online and paperbased versions. A total of 375 usable responses were collected. The demographic breakdown of respondents is given in Table 2. 
7 Journal of Internet Social Networking \& Virtual Communities

Table 2: Sample Demographics

\begin{tabular}{|c|c|c|c|c|}
\hline Gender & University 1 & University 2 & Combined & $\%$ \\
\hline Male & 107 & 101 & 208 & $56 \%$ \\
\hline \multirow[t]{2}{*}{ Female } & 110 & 56 & 166 & $44 \%$ \\
\hline & 217 & 157 & 374 & \\
\hline Time to Graduation & University 1 & University 2 & Combined & $\%$ \\
\hline Less than one year & 13 & 8 & 21 & $6 \%$ \\
\hline One year & 12 & 22 & 34 & $9 \%$ \\
\hline Two years & 51 & 67 & 118 & $31 \%$ \\
\hline Three years & 68 & 34 & 102 & $27 \%$ \\
\hline Four years & 54 & 26 & 80 & $21 \%$ \\
\hline \multirow[t]{2}{*}{ More than four years } & 19 & 1 & 20 & $5 \%$ \\
\hline & 217 & 158 & 375 & \\
\hline $\begin{array}{l}\text { Are you currently on the } \\
\text { market for your first } \\
\text { professional job? }\end{array}$ & University 1 & University 2 & Combined & $\%$ \\
\hline Yes & 28 & 39 & 67 & $18 \%$ \\
\hline \multirow[t]{2}{*}{ No } & 189 & 118 & 307 & $82 \%$ \\
\hline & 217 & 157 & 374 & \\
\hline $\begin{array}{l}\text { How often do you access your } \\
\text { account? }\end{array}$ & University 1 & University 2 & Combined & $\%$ \\
\hline Less than once a month & 5 & 0 & 5 & $1 \%$ \\
\hline Once a month & 4 & 1 & 5 & $1 \%$ \\
\hline Once a week & 17 & 8 & 25 & $7 \%$ \\
\hline Once a day & 53 & 30 & 83 & $22 \%$ \\
\hline \multirow[t]{2}{*}{ Multiple times a day } & 137 & 117 & 254 & $68 \%$ \\
\hline & 216 & 156 & 372 & \\
\hline $\begin{array}{l}\text { How long are you on your } \\
\text { account? }\end{array}$ & University 1 & University 2 & Combined & $\%$ \\
\hline Less than 10 minutes & 90 & 48 & 138 & $37 \%$ \\
\hline 10-30 minutes & 83 & 75 & 158 & $42 \%$ \\
\hline 31-60 minutes & 28 & 20 & 48 & $13 \%$ \\
\hline \multirow[t]{2}{*}{ More than 60 minutes } & 16 & 14 & 30 & $8 \%$ \\
\hline & 217 & 157 & 374 & \\
\hline
\end{tabular}

The collected data were first subjected to an exploratory factor analysis in order to determine the underlying factor structure. Given the exploratory nature of the study, the number of retained factors was determined by keeping all factors with eigen values greater than 1.0. This produced a three factor solution which explained $74.0 \%$ of the variance. The factor loadings for this solution (following Varimax rotation) can be seen in Table 3 . A review of the item loadings indicates that all three factors loaded as anticipated. 
Table 3: Loadings for Three Factor Solution

\begin{tabular}{|l|c|c|c|}
\hline \multicolumn{1}{|c|}{ Item } & Factor 1 & Factor 2 & Factor 3 \\
\hline Social Factors 1 & 0.781 & & \\
\hline Social Factors 2 & 0.716 & & \\
\hline Social Factors 3 & 0.826 & & \\
\hline Social Factors 4 & 0.842 & & \\
\hline Social Factors 5 & 0.897 & & \\
\hline Privacy Concern 1 & & 0.898 & \\
\hline Privacy Concern 2 & & 0.910 & \\
\hline Privacy Concern 3 & & 0.887 & \\
\hline Privacy Concern 4 & & 0.907 & \\
\hline Privacy Concern 5 & & 0.933 & \\
\hline Professional Online Image Concern 1 & & & 0.867 \\
\hline Professional Online Image Concern 2 & & & 0.811 \\
\hline Professional Online Image Concern 3 & & & 0.802 \\
\hline Professional Online Image Concern 4 & & & 0.801 \\
\hline Professional Online Image Concern 5 & & \\
\hline
\end{tabular}

In order to determine if any items needed to be dropped, the criteria proposed by Hinkin (1998) was used. Specifically, only items which loaded on a given factor at 0.400 or above, and/or which loaded on a given factor twice as much as any other factor were retained. Based on these criteria, no items were dropped.

As a next step in analyzing the factors, convergent and discriminant validity along with reliability were examined. Convergent validity indicates the degree to which items are measuring the same construct. In order to establish convergent validity, two criteria were used. First, there must be high item loadings on distinct factors. A review of Table 3 shows that no item loads less than 0.619 , with most items loading at 0.716 or higher. Second, the square root of the average variance extracted (AVE) for each construct must be greater than or equal to 0.707 (Fornell and Larcker, 1981). These values can be seen in Table 4 (bolded on the correlation diagonal). Inter-factor correlations are provided in the table as well. Given that the criteria are met, convergent validity is established.

Table 4: AVEs and Correlations

\begin{tabular}{|l|c|c|c|}
\hline & Social Factors & Privacy Concern & $\begin{array}{c}\text { Professional Online } \\
\text { Image Concern }\end{array}$ \\
\hline Social Factors & $\mathbf{0 . 8 4 6}$ & & \\
\hline Privacy Concern & -0.021 & $\mathbf{0 . 9 1 4}$ & $\mathbf{0 . 8 1 7}$ \\
\hline $\begin{array}{l}\text { Professional Online } \\
\text { Image Concern }\end{array}$ & $0.390^{*}$ & $0.228^{*}$ & \\
\hline
\end{tabular}
${ }^{*} \mathrm{p}<0.05$

Discriminant validity indicates the degree to which items which are supposed to measure different constructs actually differentiate between the constructs. It is established when the square root of the AVE for a particular construct is greater than the correlation between that construct and all other constructs in the model (Fornell and Larcker, 1981). Table 4 also shows that this 
criterion is met, and thus discriminant validity is established.

In order to determine the reliability of the constructs (the degree of consistency among the construct items), the internal consistency reliability was calculated using Cronbach's alpha. According to Nunnally (1978), reliability is demonstrated when Cronbach's alpha is at least 0.700 for exploratory measures. All factors in this study meet this desired level and have reliabilities above 0.890. Reliabilities for the constructs are provided in Table 5.

Table 5: Descriptive Statistics and Reliabilities

\begin{tabular}{|l|c|c|c|}
\hline & Mean & Std. Dev. & Alpha \\
\hline Social Factors & 3.611 & 1.163 & 0.919 \\
\hline Privacy Concern & 5.520 & 1.423 & 0.962 \\
\hline Professional Online Image Concern & 4.666 & 1.278 & 0.899 \\
\hline
\end{tabular}

\section{Results}

Following the development and validation of the survey instrument, linear regression was used to test the relationships between time to graduation, social factors, privacy concern, being on the market and professional online image concern. The results of the regression show that social factors, privacy concern and being on the market are significant $(\mathrm{p}<0.05)$ predictors of professional online image concern, thus supporting $\mathrm{H} 2, \mathrm{H} 3$ and $\mathrm{H} 4$. Time to graduation was not found to be a significant predictor $(\mathrm{p}=0.987)$ of professional online image concern, leaving H1 unsupported. Social factors, privacy concern and being on the market explained approximately $24 \%$ of the variance in professional online image concern (Figure 2).

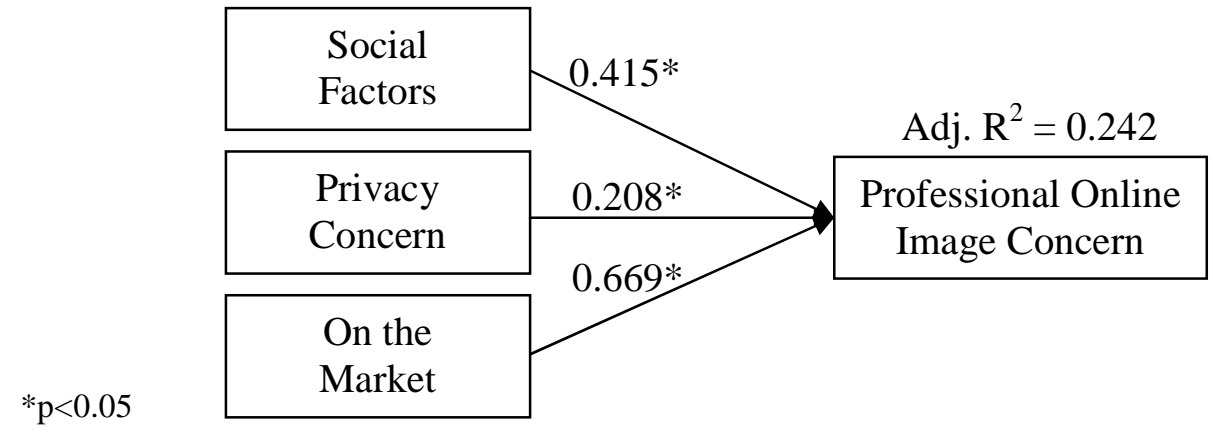

Figure 2: Research Model Results

\section{Discussion}

By developing and validating a new model of professional online image concern, this research has made a number of significant contributions to the literature. Even if many individuals are not concerned about their online privacy (Business Wire, 2010), the findings of this study indicate that those students who are concerned about privacy will also be concerned with presenting a professional online image. Thus, perhaps by encouraging students to value online privacy, faculty and other influencers may help them also increase their professional online image concern.

Second, the study confirms the positive relationship of social factors to professional online image concern. While this finding is not unexpected, it is important for two reasons. First, it reiterates the influence of 
social relationships on worldviews and decision-making. As Chrystakis and Fowler (2009) show, the influence of (non-online) social networks can be considerable, and, as with the spread of disease, behaviors can reverberate far beyond individuals' immediate social groups. More research studying the social networking phenomenon within the social networking milieu is needed to discover the ways students can influence each others' professional online image concern. At the same time, the findings suggest that social factors are not, on their own, an overwhelming construct in shaping professional online image concern and that, other factors should also be considered when trying to influence it.

Third, and perhaps most importantly, the study shows that students' identification as being on the job market is a significant predictor of professional online image concern. This finding would be unremarkable, except that those who identified themselves as being on the job market ranged from first-year to fourth-year students ( $9 \%$ of first year students; $11 \%$ of second year students; $26 \%$ of third year students; and $82 \%$ of fourth year students). Thus, whether a student chooses this status was not a function of proximity to graduation but of the student's own evaluation of him or herself as a professional. This discovery is even more striking when considered in light of another finding of the study-that time to graduation was found not to be significant as a predictor of professional online image concern, suggesting that faculty and other influencers cannot just wait for students to "grow out of" potentially self-destructive behaviors and "into" professional online image concern. How students view themselves is the key, and the earlier they can see themselves as professionals, the better. By implication, the vital question for faculty and other influencers is, "How can we get students to view themselves as professionals from day one?" That accomplishment will likely have more influence on their online behavior than any lecture or scare tactic.
Lastly, the paper lays the groundwork for future research into the factors related to professional online image concern. As examples: 1) researchers can investigate additional factors which may be useful in determining student concern for online image; 2) researchers can test factors which may moderate the relationships; and 3) researchers can investigate how professional online image concern affects posting behavior.

Clearly, continued research is needed to understand the full picture of a student's relationship to professional online image concern and to apply these findings usefully. As a preliminary effort, the model explains 24 percent of the variance, but more predictors of professional online image concern are needed. Some promising possibilities evoked by the study findings are the following:

- Student intellectual development. As the study showed, students who viewed themselves as being on the job market, no matter what their class standing, were more concerned about presenting a professional online image and thus more careful about their online behavior. How does a student's intellectual, moral, social, or emotional development (Evans et al, 2009) influence professional online image concern? These questions could be asked generally or from the perspective of age or gender. Findings could inform faculty efforts to help students burnish their professional online image.

- Student work experience. Some students have had jobs or internships in the past, while others have not. How does job history affect the way students identify themselves as professionals and their level of professional online image concern? Does having a job or internship make students aware of the importance of their professional image, including their online image? 
- Student academic experience. Many students compose a resume or go through a mock interview program as part of a required academic class. Does going through these processes help students view themselves as professionals? Does it get them to think more deeply about their professional future and the online image they should create for themselves?

- Decision making style and conditions. Daniel Kahneman's work (2011) reveals two types of decision making: System 1, based on a system in the brain that is fast and based on emotion and instinct; and System 2, a system that is slow and based on logic and deliberation. One of the conditions that causes individuals to use System 1 and to minimize risk is familiarity. Does spending large amounts of time on social networking sites cause students to become inured to the risks posed by disclosure of damaging information? What other factors affect the decision-making system students are using with regard to professional online image?

These areas hold promise in contributing constructs to extend the model of professional online image concern. In addition, exploring these questions may help universities, faculty, human resources managers, and companies encourage behaviors that will contribute positively to professional online image.

\section{Limitations and Conclusions}

As with any exploratory study, the results presented herein suffer from a couple of limitations. First, the model tested only four, of the many possible, antecedents of professional online image concern. Although the model offers good explanatory power, other factors are clearly at play and should be considered in future research. Second, the data for the study were all drawn from students in business courses. While the students represented a variety of business disciplines, the fact that the sample was composed entirely of business students could have affected the results in two ways: 1) the gender breakdown shows that the sample was skewed toward males even though the university populations were more heavily skewed to females; 2) business students may be more aware of their professional online image due to the fact that the topic is now covered in many business communication courses. Future research should attempt to mitigate these effects by drawing samples from disciplines outside business.

The research model and instrument presented in this paper have implications for researchers, practitioners and faculty. For researchers, the model provides a mechanism for better understanding the nomological network of professional online image concern. While the current model makes a significant contribution, it should only be considered a starting point. Future research will be able to expand the model by investigating the impact of such traits as risk aversion, introversion/extroversion and the need to belong, to name just a few. For practitioners, especially human resource managers, the model identifies three factors that help explain why recent graduates often have social networking profiles which present less than professional images. By better understanding the motivations of their job candidates, practitioners will be able to use social networking more effectively as a candidate screening tool. Faculty may be able to use these findings to understand students' online behavior and help them reshape it to further their career aspirations.

\section{References}

Arrington, M. (2009). "Facebook Now Nearly Twice the Size of MySpace Worldwide," Retrieved January 8, 2012 from: http://techcrunch.com/2009/01/22/facebo ok-now-nearly-twice-the-size-of-myspaceworldwide/.

Aucoin, D. (2007). "MySpace vs. Workplace," Retrieved January 8, 2012 from: 
http://www.boston.com/yourlife/articles/2 007/05/29/myspace_vs_workplace.

Badoo. (2012). Retrieved January 26, 2012 from: http://badoo.com.

Buchanan, T., Paine, C., Joinson, A. N. \& Reips, U. (2007). "Development of Measures of Online Privacy Concern and Protection for Use on the Internet," Journal of the American Society for Information Science and Technology, 58(2), 157-165.

Business Wire. (2010), Retrieved January 26, 2012 from: http://www.businesswire.com/portal/site/h ome/permalink/?ndmViewId=news_view\&n ewsId $=20100621005370 \&$ newsLang $=$ en

Chrystakis, N. A. \& Fowler, J. H. (2009). Connected: The Surprising Power of Our Social Networks and How They Shape Our Lives, Little, Brown, New York.

Economic Times. (2009), Retrieved January 26, 2012 from: http://articles.economictimes.indiatimes.co m/2009-10-30/news/27643870_1_orkutsocial-networking-user-interface.

Elzweig, B. \& Peeples, D. K. (2009). "Using Social Networking Web Sites in Hiring and Retention Decisions," S.A.M. Advanced Management Journal, 74(4), 27-35.

Evans, N. J., Forney, D. S., Guido, F. M., Patton, L. D. \& Renn, K. A. (2009). Student Development in College: Theory, Research, and Practice. Jossey-Bass, San Francisco.

Facebook. (2012), Retrieved January 26, 2012 from: http://www.facebook.com/press/info.php?s tatistics.

Fornell, C. \& Larcker, D. F. (1981). "Evaluating Structural Equations Models with Unobservable Variables and Measurement Error," Journal of Marketing Research, 18(1), 39-50.
Haefner, R. (2009). "More Employers Screening Candidates Via Social Networking Sites," Retrieved January 8, 2012 from http://www.careerbuilder.com/Article/CB1337-Getting-Hired-More-EmployersScreening-Candidates-via-SocialNetworking-Sites/.

Hinkin, T. R. (1998). "A Brief Tutorial on the Development of Measures for Use in Survey Questionnaires," Organizational Research Methods, 1(1), 104-121.

Jobvite. (2010). Retrieved January 26, 2012 from:

http://web.jobvite.com/rs/jobvite/images/J obvite $\% 202010 \% 20$ Social\%20Recruiting\%2 0Report_2.pdf.

Karl, K., Peluchette, J. \& Schlaegel, C. (2010). "Who's Posting Facebook Faux Pas? A CrossCultural Examination of Personality Differences," International Journal of Selection and Assessment, 18(2), 174-186.

Krasnova, H., Spiekermann, S., Koroleva, K. \& Hildebrand, T. (2010). "Online Social Networks: Why We Disclose," Journal of Information Technology, 25, 109-125.

McKnight, H., Carter, M. \& Clay, P. (2009). "Trust in Technology: Development of a Set of Constructs and Measures," Retrieved January 8, 2012 from: http://aisel.aisnet.org/digit2009/10/.

Miller, R. E., Salmona, M. \& Melton, J. (2011). "Students and Social Networking Sites: A Model of Inappropriate Posting," Proceedings of the Southern Association of Information Systems Conference in Atlanta, GA, 119-123.

Miller, R., Parsons, K. \& Lifer, D. (2010). "Students and Social Networking Sites: The Posting Paradox," Behaviour \& Information Technology, 29(4), 377-382.

Newman, J. (2010). "Facebook's Privacy Breach: What You Need to Know," Retrieved January 26, 2012 from: http://www.pcworld.com/article/208135/fa 
13 Journal of Internet Social Networking \& Virtual Communities

cebooks_privacy_breach_what_you_need_to_k now.html.

Nunnally, J. C. (1978). Psychometric Theory (2nd ed.), McGraw-Hill, New York.

Peluchette, J. \& Karl, K. (2010). "Examining Students' Intended Image on Facebook: 'What Were they Thinking?!'," Journal of Education for Business, 85, 30-37.

Thompson, R. L., Higgins, C. A. \& Howell, J. M. (1991). "Personal Computing: Toward a Conceptual Model of Utilization," MIS Quarterly, 15(1), 125-143.

Triandis, H. C. (1980). "Values, Attitudes, and Interpersonal Behavior," Nebraska Symposium on Motivatopn, 1979: Beliefs, Attitudes, and Values, University of Nebraska Press, Lincoln, NE. 195-259.

Trope, Y. \& Liberman, N. (2000). "Temporal Construal and Time-Dependent Changes in Preference," Journal of Personality and Social Psychology, 79, 876-889.

Venkatesh, V. Morris, M. G., Davis, G. B. \& Davis, F. D. (2003). "User Acceptance of Information Technology: Toward a Unified View," MIS Quarterly, 27(3), 425-478. 